\title{
STUDI PERBAIKAN KERUSAKAN EJECTOR PADA SISTEM PEMBUANGAN BALLAST DI KAPAL MV.SARI INDAH
}

\author{
Rio Irfan Aziz ${ }^{1 *}$, Eka Darmana ${ }^{1}$ \\ ${ }^{1}$ Program studi Teknika, Politeknik Bumi Akpelni \\ J1. Pawayatan Luhur II/17, Bendanduwur, Semarang 50235 \\ *E-mail: rioirfanaziz@gmail.com
}

\begin{abstract}
ABSTRAK
Ejector adalah komponen penting dalam sistem pembuangan ballast yang berfungsi untuk menghisap ballast dari tangki ke laut lepas menggunakan vakum dari tekanan rendah yang dihasilkan oleh nozzle dan cairan penggerak. Mengingat pentingnya peranan ejector di sistem pembuangan ballast, maka prosedur dalam pembuangan ballast harus dilakukan dengan benar sesuai dengan manual book, dan perawatan terhadap komponen di dalam sistem pembuangan ballast harus selalu diperhatikan. Tujuannya dari perawatan komponen tersebut agar selalu siap digunakan untuk kegiatan deballasting selama proses bongkar muat MV. SARI INDAH di pelabuhan.Berdasarkan hasil observasi, ada beberapa komponen dalam sistem pembuangan ballast yang mengalami kerusakan seperti ejector, manometer, dan valve penghubung antara tangki ballast dengan ejector yang harus diganti. Penggantian komponen ini dilakukan demi kelancaran proses bongkar muat. Sistem pembuangan ballast akan bekerja dengan baik apabila pengoperasiannya dilakukan sesuai dengan prosedur yang ada di manual book. Jika mengalami masalah segera melakukan perbaikan supaya tidak menghambat proses bongkar muat.
\end{abstract}

Kata Kunci: Ejector, Deballasting, Manual Book, MV. SARI INDAH.

\section{PENDAHULUAN}

Sebagai alat transportasi yang efisien kapal memiliki banyak kelebihan, dimana kapal dapat mengangkut muatan dalam jumlah yang banyak dibanding menggunakan alat transportasi yang lain. Pada saat kapal melakukan kegiatan bongkar muat di Pelabuhan maka perlu proses ballasting dan deballasting untuk menyeimbangkan posisi kapal. Ballasting adalah pengisian air laut pada tangki ballast kapal. Sedangkan deballasting adalah pembuangan air laut pada tangki ballast ke laut lepas. Pada saat kapal melakukan kegiatan pemuatan gandum di pelabuhan Vittera kota Vancouver Canada, proses deballasting mengalami masalah yaitu saat chief officer melakukan pembuangan ballast, manometer discharge ballast yang berada di ship office cargo control tidak menunjukkan adanya tekanan dan volume ballast pada tangki tidak mengalami penurunan. Setelah di lakukan pemeriksaan, ternyata ada kebocoran pada ejector di dalam sistem pembuangan ballast dan kami pun sudah menyimpulkan permasalahan bocornya ejector dalam system pembuangan ballast ini adalah tekanan air laut dari pompa general service yang masuk pada ejector terlalu besar sehingga ejector mengalami kebocoran pada bagian nozzle sea water inlet.

\section{METODE}

Metode pengumpulan data telah dilaksanakan pada 22 Juli 2017 - 08 Agustus 2018 di kapal MV SARI INDAH. Penulis menggunakan tiga metode dalam pengumpulan data, yaitu :

1. Metode observasional yang merupakan suatu metode pengumpulan data dengan melakukan pengamatan langsung terhadap subjek penelitian.

2. Metode studi pustaka yaitu teknik yang dilakukan untuk mendapatkan data atau informasi berdasarkan beberapa sumber tertulis.

3. Teknik komunikasi langsung yaitu cara penulis menanyakan langsung kepada masinis yang bertanggung jawab terhadap sistem pembuangan ballast di kapal MV SARI INDAH. 


\section{PEMBAHASAN}

Kapal ini merupakan kapal milik MSI SINGAPORE adalah kapal curah yang mengangkut berbagai muatan seperti gandum, bauksit, bijih besi, dan batu bara, baik dalam negeri maupun luar negeri. Kapal ini mempunyai DWT 89549 TON'S dengan main engine type $\mathrm{HHM}-\mathrm{B} \& \mathrm{~W}$ 5S60MC $10500 \mathrm{KW}$, kapal ini di buat tahun 2013 dengan 5 silinder dan dua ejector untuk proses pembuangan ballast pada saat kegiatan bongkar muat di pelabuhan.

Tabel 1. Shiparticular MV. SARI INDAH

\begin{tabular}{|l|l|}
\hline $\begin{array}{l}\text { NAME OF } \\
\text { SHIP }\end{array}$ & MV. SARI INDAH \\
\hline IMO & 9624964 \\
\hline CALL SIGN & 9 V2273 \\
\hline MMSi & 398832 \\
\hline FLAG & SINGAPORE \\
\hline TYPE SHIP & BULK CARRIER \\
\hline PLACE BUILD & CHINA \\
\hline YEAR BUILD & 2013 \\
\hline DWT & 89549 TON \\
\hline GRT & 48065 TON \\
\hline NRT & 27700 TON \\
\hline LOA & $229,00 \mathrm{M}$ \\
\hline LBP & $221,00 \mathrm{M}$ \\
\hline BREADHT & $36,80 \mathrm{M}$ \\
\hline DEPTH & $19,90 \mathrm{M}$ \\
\hline $\begin{array}{l}\text { MAIN } \\
\text { ENGINE }\end{array}$ & HHM-B\&W 5S60MC \\
\hline M.R.C & $10500 \mathrm{KW}$ \\
\hline FUEL & HFO \\
\hline $\begin{array}{l}\text { EJECTOR } \\
\text { BALLAST }\end{array}$ & $\begin{array}{l}\text { STARIT ( PORT \& } \\
\text { STAARD) }\end{array}$ \\
\hline
\end{tabular}

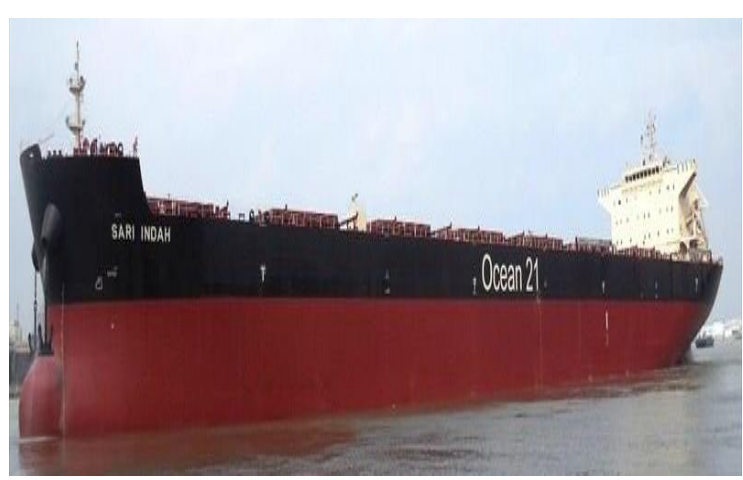

Gambar 1. MV. SARI INDAH

Adapun keunggulan - keunggulan yang pada sistem stripping ballast menggunakan ejector ini adalah :

1. Menghemat pengeluaran biaya untuk perawatan dan perbaikan.

Dalam hal ini jika proses pembuangan ballast menggunakan pompa tersendiri maka pengeluaran untuk biaya perawatan dan perbaikan akan bertambah dan spare part yang digunakan akan lebih banyak sehingga jika dilihat dari sisi keuangan maka sistem stripping ballast menggunakan ejector lebih menguntungkan.

2. Daya yang digunakan untuk proses pembuangan ballast lebih kecil.

Apabila proses pembuangan ballast menggunakan ejector tanpa menggunakan pompa sendiri maka daya yang digunakan untuk proses deballasting menjadi lebih kecil jika dibandingkan pembuangan ballast menggunakan pompa tersendiri. Cukup menggunakan satu buah generator sudah bisa digunakan untuk memenuhi kebutuhan daya yang diperlukan dalam proses pembuangan ballast karena daya yang dibutuhkan untuk menghidupkan pompa general service kecil. Sehingga apabila dilihat dari sisi keefesienan daya maka pembuangan ballast dengan ejector lebih efisien daripada menggunakan pompa sendiri. 


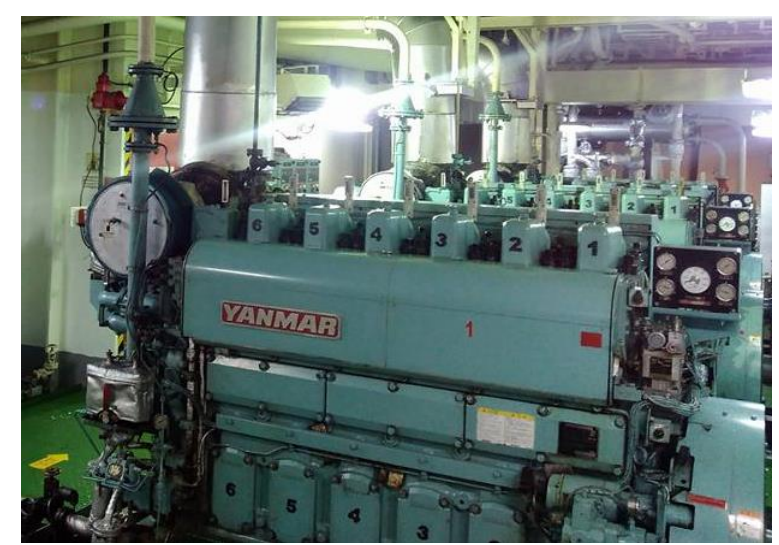

Gambar 2. Generator MV.SARI INDAH

3. Lebih menghemat tempat / space.

Jika sistem pembuangan ballast menggunakan ejector tanpa menggunakan pompa sendiri tentu lebih menghemat tempat daripada sistem pembuangan ballast yang menggunakaan pompa sendiri. Sehingga space pada engine room bisa digunakan untuk hal yang lebih bermanfaat.

4. Jika terjadi masalah pada sistem lebih mudah ditemukan.

Karena sistem pembuangan ballast menggunakan ejector lebih sederhana daripada menggunakan pompa sendiri, maka jika terjadi masalah dalam sistem pembuangan ballast lebih mudah ditemukan. Dan waktu untuk perbaikan pada saat terjadi masalah pada sistem lebih efektif.

Kerusakanejector pada sistem pembuangan ballast tentu tidak diinginkan. Namun ada beberapa keadaan yang tidak di inginkan bisa terjadi apabila prosedur dalam pembuangan ballast tidak di laksanakan sesuai manual book seperti yang dialami di atas kapal. Sebagai seorang engineer di atas kapal di tuntut untuk peka terhadap semua kinerja dari permesinan yang sedang beroperasi. Berikut ini merupakan permasalahan yang terjadi pada sistem pembuangan ballast selama observasi di atas kapal dan hal hal yang dapat di lakukan untuk mengantisipasi pada saat melakukan perbaikan maupun perawatan.
Dari hasil pengamatan menunjukkan bahwa ada beberapa hal yang terjadi pada sistem pembuangan ballast.

1. Volume tangki ballast saat proses pembuangan ballast tidak berkurang.

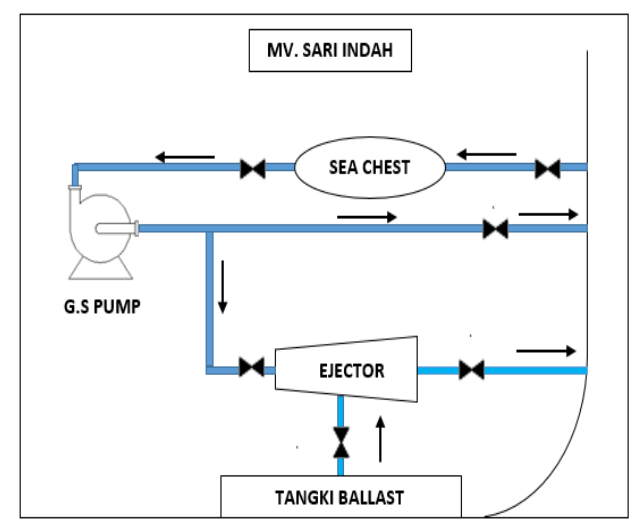

Gambar 3. Sistem Pembuangan Ballast

Dalam hal ini hal yang perlu diperhatikan adalah prosedur pembuangan ballast yang sesuai dengan aturan yang telah ditentukan manual book. Sehingga proses pembuangan ballast dapat berjalan dengan lancar dan proses bongkar muat di pelabuhan tidak mengalami keterlambatan atau delay.

Prosedur yang benar pada saat proses pembuangan ballast :

a.Buka kran inlet air laut menuju sea chest.

b.Buka kran inlet air laut dari sea chest menuju pompa general service.

c.Buka kran overboard dari pompa general service.

d.Nyalakan pompa general service.

e.Buka kran sea water outlet dari ejector.

f. Buka kran sea water inlet pada ejector.

g.Tutup kran overboard dari pompa general service secara perlahan lalu adjust sampai tekanan pada sea water inlet pada ejector cukup untuk membuat tekanan rendah pada vacuum chamber yaitu pada tekanan $7 \mathrm{~kg} / \mathrm{cm}^{2}$.

h. Setelah ejector vakum buka secara perlahan kran inlet dari tangki ballast.

i. Perhatikan manometer discharge ballast, pastikan ballast dari tangki keluar overboard. 
j. Setelah semua selesai dan normal, cek secara berkala sitem pembuangan ballast ini supaya apabila terjadi masalah segera diketahui.

2. Manometer vakum pada ejector yang tidak berfungsi dengan baik.

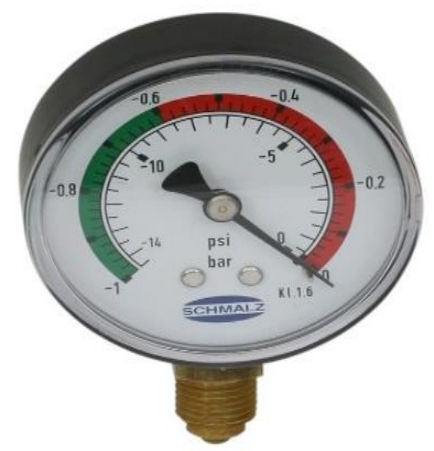

Gambar 4. Manometer Vakum pada Ejector

Manometer vakum merupakan komponen penting pada ejector. Dengan manometer vakum ini kita bisa tahu apakah vacuum chamber pada ejector sudah vakum dengan baik atau tidak. Jika terjadi kerusakan segera lakukan kalibrasi pada manometer yang telah rusak.

3. Kebocoran valve pada sistem.

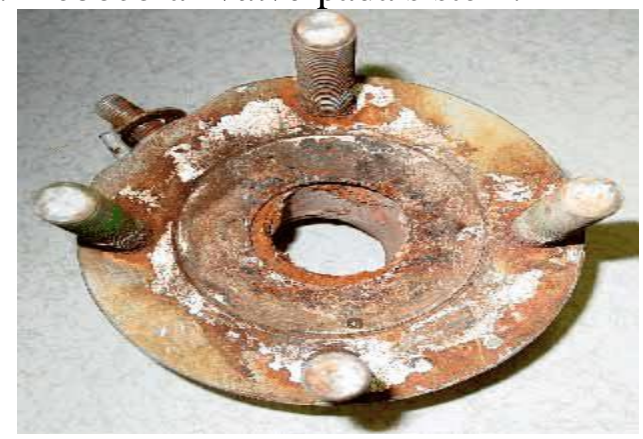

Gambar 5. Korosi pada Valve

Kebocoran valve dari sistem disebabkan karena korosi dalam valve yang mengakibatkan keroposnya bagian dalam valve. Valve dalam sistem pembuangan ballast ini mengalirkan air laut sehingga mudah terjadi korosi.

4.Penggantian ejector pada sistem.

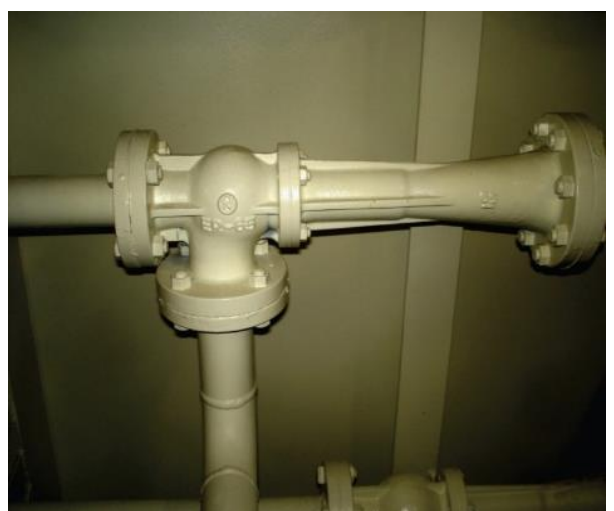

Gambar 6. Penggantian Ejector

Penggantian ejector dilakukan karena ejector yang rusak sudah tidak layak digunakan kembali sehingga perlu diganti dengan yang baru karena kerusakan pada ejector yang lama sudah sangat fatal sehingga tidak bisa diperbaiki dan sudah tidak layak untuk digunakan kembali. Dan tidak adanya ready spare part untuk bagian ejector yang mengalami kerusakan membuat kami mengganti seluruh komponen ejector yang telah rusak ke ejector yang baru.

Proses penggantian pada ejector antara lain:

1. Kerusakan pada nozzle ejector.

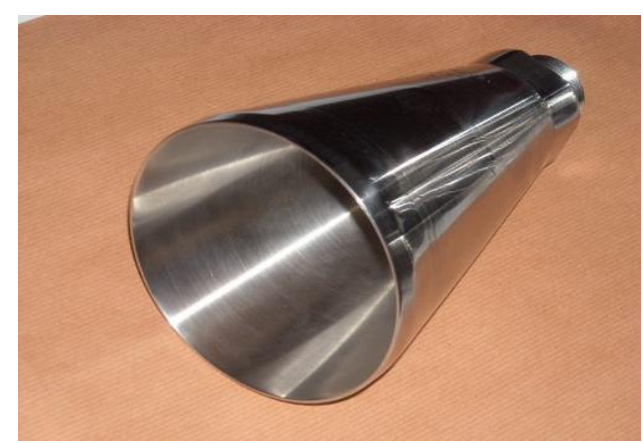

Gambar 7.Nozzle Ejector

Kerusakan utama pada ejector adalah nozzle pada ejector yang pecah karena tekanan air laut yang masuk ke dalam nozzle ejector terlalu besar dan melebihi dari prosedur yang ditentukan yaitu 7 $\mathrm{kg} / \mathrm{cm}^{2}$ tetapi tekanan yang diberikan 9 $\mathrm{kg} / \mathrm{cm}^{2}$. Karena tidak ada ready spare part untuk nozzle ejector ini dan model nozzle pada ejector menyatu dengan ejector tersebut sehingga dilakukan penggantian secara keseluruhan. 
2. Gasket dan O-Ring ejector rusak.

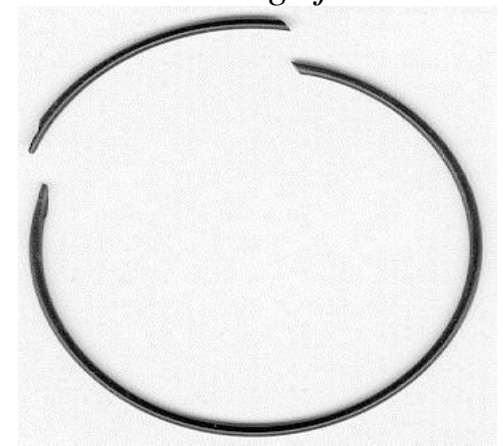

Gambar 8.O-Ring yang rusak

Karena terjadi kebocoran dalam ejector yaitu bagian nozzle ejector yang rusak menyebabkan gasket dan o-ring yang ada dalam ejector juga mengalami kerusakan. Tidak adanya ready spare part untuk gasket dan o-ring adalah salah satu alasan digantinya ejector dengan yang baru karena tidak ada ready spare part untuk ejector dalam sistem pembuangan ballast. 3. Pengetesan terhadap ejectorbaru.

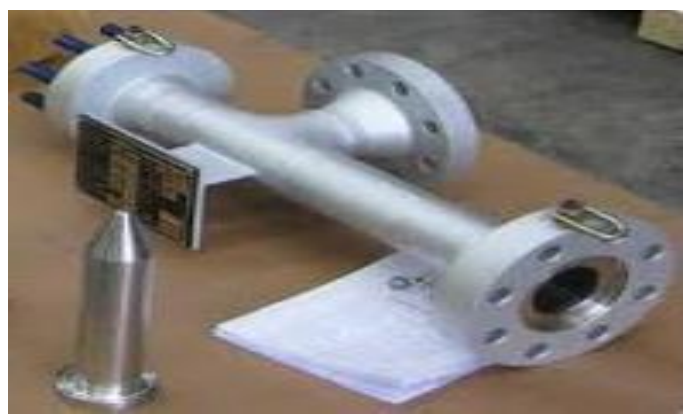

Gambar 9. Ejector baru di kapal.

Setelah dilakukan penggantian ejector yang rusak dengan ejector yang baru maka hal yang wajib dilakukan adalah pengetesan. Pada saat pengetesan ejector yang baru, semua sistem pembuangan ballast dilakukan sesuai prosedur dan ejector yang baru bekerja dengan normal dan vakum pada manometer normal dan tidak ada masalah.

\section{KESIMPULAN}

Kesimpulan yang diambil antara lain,

1. Pentingnya pengetahuan terhadap prosedur dalam pembuangan ballast sehingga proses pembuangan ballast berjalan dengan lancar dan tidak menyebabkan keterlambatan atau delay pada saat proses bongkar muat di pelabuhan.

2. Kerusakan ejector disebabkan karena tekanan air laut yang masuk ke dalam sistem terlalu besar tidak sesuai dengan instruksi manual book di kapal. Karena kurangnya perhatian dari masinismasinis di kapal terjadi kerusakan pada saat ejector beroperasi dan mengganggu proses bongkar maupun muat.

3. Tidak ada ready spare part untuk komponen pada ejector sehingga ejector yang hanya mengalami kerusakan pada nozzle, nozzle, gasket, dan o-ring harus diganti secara keseluruhan.

4. Kurangnya perhatian dari awak kapal bagian mesin pada saat proses pembuangan ballast sehingga pada saat terjadi kerusakan pada sistem tidak ada yang mengetahui karena tidak dilakukan pengecekan secara berkala.

5. Perusahaan terlalu membatasi biaya untuk perawatan komponenkomponen pesawat bantu.

\section{DAFTAR PUSTAKA}

Alawadhi, Khaled, 2017, Numerical Investigation of a Liquid-Gas Ejector Used For Shipping Ballast Water Treatment,International Journal of Applied Engineering Research, Vol. 12, PP. 4663-4674.

Choi, Jeongju, 2014, Optimal Control of Manufacturing Procedure of Ballast System, Journal of Engineering Manufacture, Vol. 2, PP. 1252-1258.

Dumitrache, Constantin, 2016, Design and Flow Modelling of Ballast Tank In-line Ejector, Journal of Designing a Water In-Line Ejector, Vol. 34, PP. 65-69.

Song, Xue Guan, 2014,Investigation of A Liquid-Gas Ejector Used for Shipping Ballast Water Treatment, Mathematical Problems in Engineering,Vol. 2, PP. 203210. 